\title{
Epidemiology and management of painful procedures in children in Canadian hospitals
}

\author{
Bonnie J. Stevens RN PhD, Laura K. Abbott MSc, Janet Yamada RN MSc, Denise Harrison RN PhD, \\ Jennifer Stinson RN PhD, Anna Taddio PhD, Melanie Barwick PhD, Margot Latimer RN PhD, \\ Shannon D. Scott RN PhD, Judith Rashotte RN PhD, Fiona Campbell MD, G. Allen Finley MD; \\ for the CIHR Team in Children's Pain
}

\begin{abstract}
Background: Children being cared for in hospital undergo multiple painful procedures daily. However, little is known about the frequency of these procedures and associated interventions to manage the pain. We undertook this study to determine, for children in Canadian hospitals, the frequency of painful procedures, the types of pain management interventions associated with painful procedures and the influence of the type of hospital unit on procedural pain management.
\end{abstract}

Methods: We reviewed medical charts for infants and children up to 18 years of age who had been admitted to 32 inpatient units at eight Canadian pediatric hospitals between October 2007 and April 2008. We recorded all of the painful procedures performed and the pain management interventions that had been implemented in the 24-hour period preceding data collection. We performed descriptive and comparative (analysis of variance, $\chi^{2}$ ) analyses.

Results: Of the 3822 children included in the study, $2987(78.2 \%)$ had undergone at least one painful procedure in the 24-hour period preceding data collection, for a total of 18929 painful procedures (mean 6.3 per child who had any painful procedure). For 2334 (78.1\%) of the 2987 children who had a painful procedure, a pain management intervention in the previous 24 hours was documented in the chart: $1980(84.8 \%)$ had a pharmacologic intervention, $609(26.1 \%)$ a physical intervention, $584(25.0 \%)$ a psychologic intervention and $753(32.3 \%)$ a combination of interventions. However, for only $844(28.3 \%)$ of the 2987 children was one or more pain management interventions administered and documented specifically for a painful procedure. Pediatric intensive care units reported the highest proportion of painful procedures and analgesics administered.

Interpretation: For less than one-third of painful procedures was there documentation of one or more specific pain management interventions. Strategies for implementing changes in pain management must be tailored to the type of hospital unit.
Competing interests: Anna Taddio has received a clinical trial grant from Gebauer; has received study drugs for clinical trials from Hawaii Medical, Ferndale Laboratories and Gebauer; and has received honoraria for workshop presentations from Wyeth. G. Allen Finley has served as a consultant on study design for J\&J Research \& Development (for an unrelated study). No competing interests declared by Bonnie J. Stevens, Laura K. Abbott, Janet Yamada, Denise Harrison, Jennifer Stinson, Melanie Barwick, Margot Latimer, Shannon D. Scott, Judith Rashotte and Fiona Campbell.

This article has been peer reviewed.

Correspondence to: Dr. Bonnie Stevens, b.stevens@utoronto.ca

CMAJ 2011. DOI:10.1503 /cmaj.101341

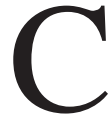
hildren who are being cared for in hospital undergo multiple painful procedures daily. ${ }^{1-3}$ The association between pain and negative physiologic, emotional and psychologic consequences is well established. ${ }^{4.5}$ In addition, the development of international pain guidelines $^{6-8}$ and an expanding body of research on the effectiveness and safety of pain management strategies ${ }^{2,3}$ have led to improvements in assessing and managing procedural pain..$^{910}$ Because it is impossible to completely eliminate the pain experienced by pediatric inpatients, effective pain management is crucial. However, the use of specific interventions for procedural pain management within various types of hospital units is unknown.

The purpose of this study was to determine, for children being cared for in hospital, the frequency of painful procedures, the types of pain management interventions associated with painful procedures and the influence of the type of hospital unit on the management of procedural pain.

\section{Methods}

\section{Study centres}

Of the 15 children's hospitals in Canada at the start of the study, eight met our requirements of having four or more distinct units, excluding psychiatric units, with 30 or more beds. Psychiatric units and children on these units were ineligible because of the potential for adverse psychologic responses to pain and the low incidence of painful procedures on these units. The eight eligible sites were all urban-based university-affiliated pediatric hospitals that agreed, 
upon invitation, to participate in the Canadian Institutes of Health Research (CIHR) Team in Children's Pain program of research and provided letters of support.

Study units within each site were eligible for inclusion if they had a distinct geographic location and administrative structure; admitted children for periods longer than 24 hours; administered painful procedures to inpatients; and had pharmacologic, physical and psychologic interventions available for managing pain. Each site had a site investigator from the CIHR Team in Children's Pain, who met with unit managers to explain the study and to determine which units met the criteria and were interested in participating. At sites with more than four eligible units, we randomly selected four units to participate, including at least one medical, one surgical and one critical care unit. We hired a research nurse as part of the study team at each site. This person's duties included orienting unit staff to the study through standardized presentations during staff meetings, as well as collecting the data for the study. All site investigators and research nurses attended a two-day training session to review the study protocol and learn about procedures for collecting data electronically.

The study protocol was approved first by the Research Ethics Board at the primary site (The Hospital for Sick Children, Toronto, Ontario) and then by the research ethics boards of the other participating hospitals.

\section{Study participants and data collection}

Infants and children up to 18 years of age who were admitted to the study units for more than 24 hours were eligible for inclusion. The research nurses collected data from 30 charts per unit over four consecutive four- to six-week periods between October 2007 and April 2008, for a total of 120 charts per unit. More specifically, the research nurses reviewed the charts of the first 30 consecutively admitted children meeting the inclusion criteria during each data collection period. The research nurses performed a comprehensive examination of all aspects of the chart to locate data on the frequency of all skin-breaking painful procedures (e.g., heel lance, finger prick, surgery), all non-skin-breaking painful procedures (e.g., suctioning, mobilization) ${ }^{11,12}$ and any pharmacologic, physical or psychologic pain management interventions over the 24-hour period (midnight to midnight) closest to the time when the chart was reviewed.

The research nurses entered all data into a centralized web-based relational database (the Canadian Pediatric Pain Research database; www.childrenspainstudy.ca), which was created with Oracle version 9 by the Centre for Computational Biology at the core site (The Hospital for Sick Children). Data entry was based on a predetermined list of variables arranged over multiple online pages. The system included built-in validation checks and skipped-question prompts to ensure completeness and accuracy of data entry. The data entry process was pilot-tested at each site for feasibility, accuracy and security of data transferred into the database.

\section{Statistical analyses}

We conducted initial analyses of the data for demographic characteristics, painful procedures and pain management interventions obtained from each unit to assess completeness and consistency. We calculated means, standard deviations (SDs), medians and interquartile ranges (IQRs) for continuous data and frequency counts and proportions for categorical data. We performed Kruskal-Wallis tests to compare the median number of painful procedures across sites and unit types. We used contingency table $\chi^{2}$ tests for binary data, such as whether or not a particular type of intervention had been used. To adjust for lack of independence (caused by sampling of multiple patients from the same hospital unit), we used Taylor linearization methods for simple bivariate associations (e.g., Rao-Scott $\chi^{2}$ tests). ${ }^{13}$ In addition to accounting for the clustered nature of the data, these methods are robust to misspecification of the correlation within clusters, when the structure of the correlations is unknown. ${ }^{14}$ We specified a significance value of $p=0.05$ for all statistical tests.

\section{Results}

Between October 2007 and April 2008, we reviewed the medical charts of 120 children per unit from 32 inpatient units (14 medical, 8 surgical, 10 critical care) at the eight research sites, for a total of 3840 children. Demographic data were missing for 4 children $(0.1 \%)$, and 14 patients $(0.4 \%)$ did not meet the inclusion criterion of age less than 19 years. We excluded these 18 cases, which reduced the final sample to 3822 children: 1684 (44.1\%) from medical units, 1183 (31.0\%) from critical care units and 955 (25.0\%) from surgical units.

In the medical and pediatric intensive care units (ICUs), the most common reasons for admission were related to the respiratory and circulatory systems (e.g., pneumonia, congenital heart diseases). Oncology-related diagnoses were also common in the medical units. In the surgical units, the most common types of surgeries performed were related to general surgery (e.g., 
appendectomy) and orthopedics (e.g., for scoliosis or fracture). The most frequent diagnoses for neonates in the neonatal ICUs were related to prematurity and congenital conditions. Additional sample characteristics are presented in Table 1.

\section{Numbers and types of procedures}

Of the 3822 children included in the analysis, 2987 (78.2\%) had one or more painful procedures recorded for the 24-hour period preceding data collection. The total number of painful procedures was 18929 (mean 6.3 per child who underwent a painful procedure, SD 7.0, median 3.0, range $1-50$, IQR 2.0-6.0). The 10 most commonly performed procedures accounted for $14294(75.5 \%)$ of all procedures. The most commonly performed procedures (i.e., administered to at least $1 \%$ of patients in the study sample) in each category of pain severity and the types of interventions administered within the 24-hour period preceding data collection for patients who underwent these procedures are summarized in Table 2.

Children in critical care units (pediatric and neonatal ICUs) underwent many more painful procedures than those on medical and surgical units: for children in ICUs, median 10.0 per day (IQR 4.0-17.0, mean 11.5, SD 8.7); for children on medical units, median 2.0 per day (IQR 1.0-

\begin{tabular}{|c|c|}
\hline Characteristic & $\begin{array}{l}\text { No. }(\%) \text { of } \\
\text { patients } \\
n=3822\end{array}$ \\
\hline \multicolumn{2}{|l|}{ Age, yr } \\
\hline$<1$ & $1402 \quad(36.7)$ \\
\hline $1-3$ & $559 \quad(14.6)$ \\
\hline $4-6$ & $322 \quad(8.4)$ \\
\hline $7-12$ & $712 \quad(18.6)$ \\
\hline $13-18$ & $827 \quad(21.6)$ \\
\hline Male sex & $2031 \quad(53.1)$ \\
\hline \multicolumn{2}{|l|}{ Primary diagnosis } \\
\hline Acute & 3377 (88.4) \\
\hline Chronic & $445 \quad(11.6)$ \\
\hline \multicolumn{2}{|l|}{ Secondary diagnosis } \\
\hline Acute & $178 \quad(4.7)$ \\
\hline Chronic & $695 \quad(18.2)$ \\
\hline Surgery in previous $24 \mathrm{~h}$ & $154 \quad(4.0)$ \\
\hline $\begin{array}{l}\text { Mechanical tracheal } \\
\text { ventilation }\end{array}$ & $250 \quad(6.5)$ \\
\hline $\begin{array}{l}\text { Continuous infusion of } \\
\text { sedative or analgesic }\end{array}$ & $361 \quad(9.4)$ \\
\hline
\end{tabular}

4.0, mean 3.4, SD 3.2); and for children on surgical units, median 2.0 per day (IQR 1.0-4.0, mean 3.2, SD 2.8) $(p<0.001$ for differences across unit types).

A greater proportion of children in critical care units underwent at least one painful procedure within the 24-hour period preceding data collection (1095 of 1183 [92.6\%]) than was the case for children on medical units (1212 of 1684 [72.0\%]) and surgical units (680 of 955 [71.2\%]). In particular, children in pediatric ICUs underwent a median of 12.0 painful procedures daily (IQR 6.0-18.0, mean 13.1, SD 8.8), whereas infants in neonatal ICUs underwent a median of 5.0 painful procedures daily (IQR 2.0-11.0, mean 7.2, SD 6.7) ( $p<0.001$, Kruskal-Wallis test).

\section{Management of painful procedures}

Overall, for 2334 (78.1\%) of the 2987 children who underwent a painful procedure, a pain management intervention had been documented in the 24-hour period preceding data collection. Of these children, 1980 (84.8\%) had documentation of at least one pharmacologic intervention (analgesic and/or adjuvant analgesic), 609 (26.1\%) had a physical intervention, $584(25.0 \%)$ had a psychologic intervention, and 753 (32.3\%) received a combination of interventions (Table $3)$. Of the 1980 children who received a pharmacologic intervention, $348(17.6 \%)$ were receiving a continuous opioid infusion (i.e., fentanyl, hydromorphone or morphine). The most frequent interventions are summarized in Table 3.

For $844(28.3 \%)$ of the 2987 children who underwent a painful procedure, there was documentation of a pain management intervention administered specifically for a painful procedure. Of these children, 791 (93.7\%) had a pharmacologic intervention, $80(9.5 \%)$ had a physical intervention, $21(2.5 \%)$ had a psychologic intervention, and $44(5.2 \%)$ had a combination of interventions. About $21 \%$ of children who had a pharmacologic intervention associated with a specific painful procedure (168 of 791) were receiving a continuous opioid infusion (i.e., fentanyl, hydromorphone or morphine).

The proportion of children who received a pharmacologic or physical intervention increased with increasing numbers of procedures administered to an individual child. On the basis of the skewness of the data $(S=2.04)$, we used the following categories for this analysis: one to three painful procedures, four to six painful procedures and more than seven painful procedures. Of the 1498 children who underwent one to three painful procedures, only $226(15.1 \%)$ received a pharmacologic intervention, whereas 166 
Table 2: Most frequently performed painful procedures, arranged by pain severity, and pain management interventions administered to children who underwent these procedures*

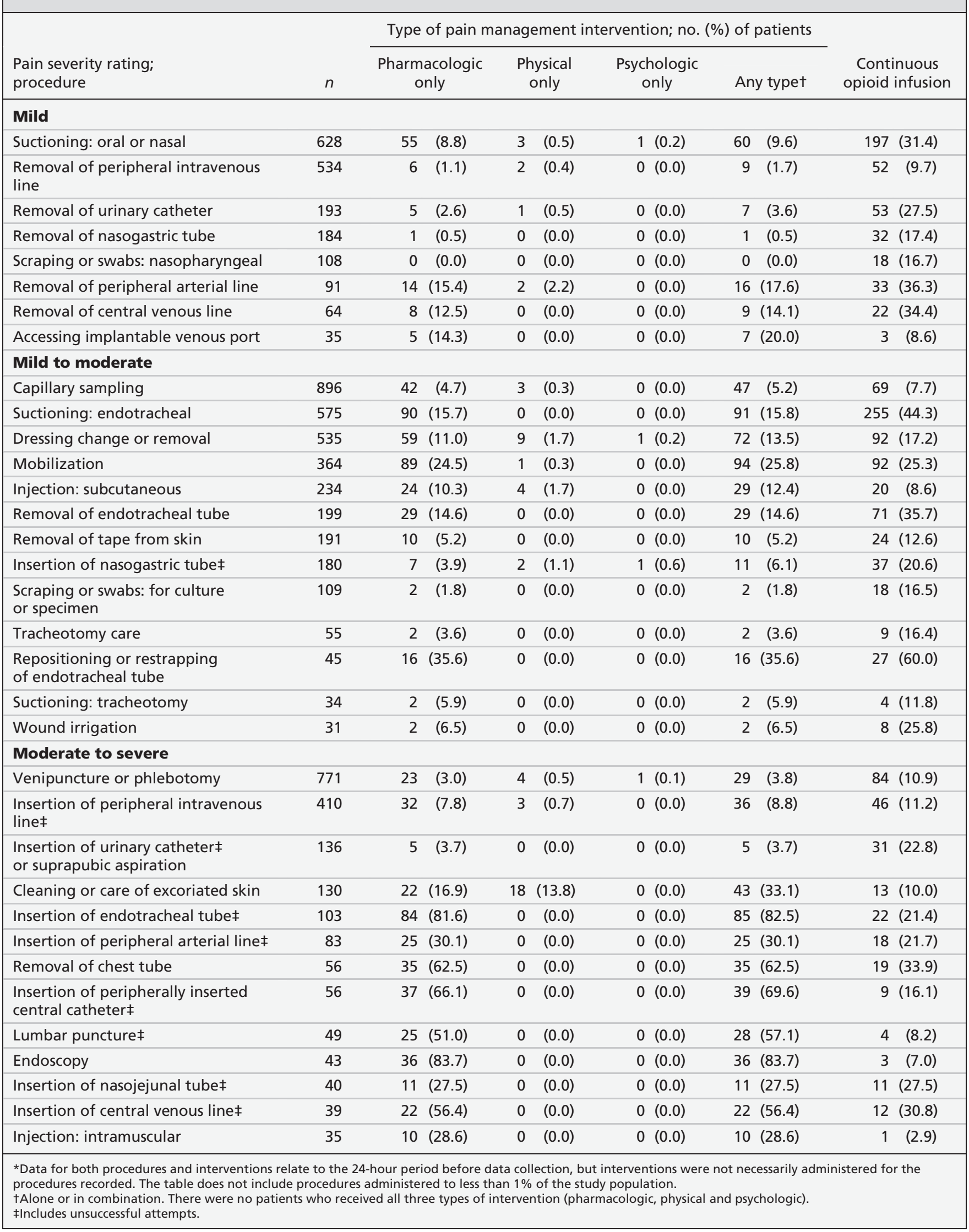


$(30.8 \%)$ of the 539 who underwent four to six procedures and $399(42.0 \%)$ of the 950 who had seven or more procedures received pharmacologic interventions $(p<0.001$, contingency table $\chi^{2}$ test). Similarly, $1.4 \%$ (21/1498) of the children who underwent one to three painful procedures received a physical intervention, whereas $3.9 \%(21 / 539)$ of those who had four to six procedures and $4.0 \%$ (38/950) of those who had seven or more procedures received a physical intervention ( $p=0.001$, contingency table $\chi^{2}$ test). In contrast, a significant inverse relationship was noted for psychologic interventions: $0.9 \%(19 / 2037)$ of children having one to six procedures received a psychologic intervention, whereas only $0.2 \%$ (2/950) of those who had seven or more procedures received this type of intervention $\left(p=0.015\right.$, contingency table $\chi^{2}$ test).

Children in pediatric ICUs were more likely than those in other types of units to receive pharmacologic and physical interventions for painful procedures (Table 4).

\section{Interpretation}

More than three-quarters (78.2\%) of the children in our sample had undergone at least one painful procedure in the 24-hour period preceding data collection, with an average of 6.3 procedures per child (range 1-50). Similarly, for the majority (78.1\%) of children who underwent a painful procedure, some type of pain management intervention was documented in the same time period. For these children, pharmacologic interventions were administered most frequently $(84.8 \%)$, followed by physical interventions (26.1\%), psychologic interventions $(25.0 \%)$ and combinations of interventions $(32.3 \%)$. However, only about one-quarter $(28.3 \%)$ of the interventions were specifically linked with a painful procedure. Pediatric ICUs reported the highest proportion of painful procedures and analgesics administered.

Researchers have reported the untoward consequences of pain in children for decades. ${ }^{4,15,16}$ Although the frequency of painful procedures documented in our study was lower than in previous studies, it remains unacceptably high and varies considerably across patients and types of hospital units. Carbajal and colleagues ${ }^{1}$ reported that neonates from multiple neonatal ICUs underwent a mean of 12 (SD 8) painful procedures daily, and $79.2 \%$ of these procedures were performed without specific analgesic. Others have reported similar findings. ${ }^{9,10,17-19}$ Thus, the scope of this issue is broad and universal.

There has been some improvement in the pro- portion of children who received any pain management intervention during the 24-hour period preceding data collection, relative to previous studies. ${ }^{20}$ However, despite an abundance of evidence on effective pain management strategies, ${ }^{2,3}$ only a small proportion of children in our study had interventions specifically linked to the painful procedure. Pharmacologic interventions were documented most frequently, especially in pediatric ICUs. Our findings contrast with prospective observational studies conducted in neonatal ICUs, where nonpharmacologic interventions were used more frequently than pharmacologic interventions. For example, in another study, ${ }^{19}$ our research group found that nonphar-

Table 3: Most frequently performed pain management interventions for children undergoing at least one painful procedure

\begin{tabular}{|c|c|c|c|}
\hline Intervention & $\begin{array}{l}\text { No. of patients } \\
\text { receiving } \\
\text { intervention }\end{array}$ & $\begin{array}{c}\% \text { of patients } \\
\text { in intervention } \\
\text { category }\end{array}$ & $\begin{array}{l}\% \text { of all } \\
\text { patients } \\
n=2987\end{array}$ \\
\hline Pharmacologic & $n=1980$ & & \\
\hline \multicolumn{4}{|l|}{ Opioid } \\
\hline Morphine & 351 & 17.7 & 11.8 \\
\hline Fentanyl & 300 & 15.2 & 10.0 \\
\hline Codeine & 236 & 11.9 & 7.9 \\
\hline \multicolumn{4}{|l|}{ NSAID } \\
\hline Ketorolac & 82 & 4.1 & 2.7 \\
\hline Naproxen & 40 & 2.0 & 1.3 \\
\hline Ibuprofen & 20 & 1.0 & 0.7 \\
\hline \multicolumn{4}{|l|}{ Non-opioid } \\
\hline Acetaminophen & 1397 & 70.6 & 46.8 \\
\hline \multicolumn{4}{|l|}{$\begin{array}{l}\text { Topical or local } \\
\text { anesthetic }\end{array}$} \\
\hline Bupivacaine & 50 & 2.5 & 1.7 \\
\hline Lidocaine & 46 & 2.3 & 1.5 \\
\hline Liposomal lidocaine & 32 & 1.6 & 1.1 \\
\hline Sucrose & 36 & 1.8 & 1.2 \\
\hline \multicolumn{4}{|l|}{ Adjuvant } \\
\hline Ketamine & 140 & 7.1 & 4.7 \\
\hline Clonidine & 50 & 2.5 & 1.7 \\
\hline Physical & $n=609$ & & \\
\hline Positioning & 274 & 45.0 & 9.2 \\
\hline Heat or cold therapy & 124 & 20.4 & 4.2 \\
\hline $\begin{array}{l}\text { Non-nutritive } \\
\text { sucking }\end{array}$ & 106 & 17.4 & 3.5 \\
\hline Psychologic & $n=584$ & & \\
\hline Preparation or education & 214 & 36.6 & 7.2 \\
\hline Reassurance & 158 & 27.1 & 5.3 \\
\hline Deep breathing & 103 & 17.6 & 3.4 \\
\hline Behavioural distraction & 57 & 9.8 & 1.9 \\
\hline
\end{tabular}


macologic interventions (physical $84.0 \%$, behavioural $51.2 \%$ and environmental $28.4 \%$ ) were implemented more frequently than pharmacologic interventions (23.2\%). Similarly, Johnston and associates ${ }^{10}$ reported that more than $70 \%$ of infants received nonpharmacologic interventions for heel lance in neonatal ICUs. Carbajal and colleagues ${ }^{1}$ reported that only $2 \%$ of painful procedures in neonatal ICUs were managed with pharmacologic interventions, whereas $18 \%$ were managed with nonpharmacologic interventions and $20 \%$ with a combination of pharmacologic and nonpharmacologic interventions. Study design and the exclusivity of the setting (i.e., neonatal ICUs only) could account for these differences in relation to the present study. In addition, the more frequent use of nonpharmacologic interventions may reflect beliefs associated with pain in infants, safety concerns related to the administration of analgesics (e.g., opioids) $)^{21-24}$ or an appreciation of the best evidence (e.g., Cochrane systematic review on sucrose ${ }^{25}$ ). The use of psychologic interventions decreased with higher numbers of painful procedures.

The type of hospital unit also influenced pain management practices. For example, medical units documented the most psychologic interventions for managing pain. Health care professionals on these units may see more children with chronic pain, and their use of these interventions for chronic pain may cross over to management of acute pain. Similarly, in critical care and surgical units, more emphasis was placed on pharmacologic pain management, perhaps because of a closer association with anesthesiologists and patient-controlled analgesia. Units that accessed specialist pain services also had less frequent administration of analgesia, perhaps because the number of patients with complex needs seen on these units was limited or because staff members had less perceived "ownership" of overall pain management for other patients on the unit. A systematic review of the effectiveness of acute pain teams in improving the quality of analgesia and postoperative outcomes for adults was inconclusive. ${ }^{26}$ However, Werner and coauthors ${ }^{27}$ reported that acute pain services were associated with reduced intensity of pain.

\section{Limitations}

Design limitations suggest that the results of this study should be interpreted with caution. To accommodate the large sample size and to standardize data collection, our design involved a retrospective examination of medical charts. Incomplete and variable documentation prevented analyses by standardized diagnostic category or categorization of the intensity of procedural pain. Furthermore, documentation may not always have reflected actual practices, especially in relation to physical and psychologic interventions and how pharmacologic interventions were combined or linked to specific procedures. We had no opportunity to observe or question health care professionals about their rationale or preferences related to pain practices. Although the use of corrections for multiple testing during analysis helped to control type I error, type II error may have become inflated. The reporting of precise unadjusted $p$ values allows for the degree of significance to be evaluated within the context of all tests examined.

\section{Conclusions}

Decreases in the number of painful procedures performed and improvements in pain management associated with procedures are essential to relieve pain and suffering and to capitalize on the associated benefits for patients and the decreased use of health care resources. ${ }^{28}$ Careful

\begin{tabular}{|c|c|c|c|c|c|c|c|c|c|}
\hline \multirow[b]{2}{*}{$\begin{array}{l}\text { Type of } \\
\text { unit }\end{array}$} & \multirow[b]{2}{*}{$\begin{array}{c}\text { No. of } \\
\text { patients }\end{array}$} & \multirow[b]{2}{*}{$\begin{array}{l}\text { No. of } \\
\text { procedures }\end{array}$} & \multicolumn{2}{|c|}{$\begin{array}{c}\text { Any pharmacologic } \\
\text { interventiont }\end{array}$} & \multicolumn{3}{|c|}{$\begin{array}{l}\text { Any physical } \\
\text { intervention }\end{array}$} & \multicolumn{2}{|c|}{$\begin{array}{l}\text { Any psychologic } \\
\text { intervention§ }\end{array}$} \\
\hline & & & $\begin{array}{l}\text { No. }(\%) \text { of } \\
\text { patients }\end{array}$ & $\begin{array}{l}95 \% \mathrm{Cl} \text { for } \\
\text { percentage }\end{array}$ & $\begin{array}{r}\text { No. ( } \\
\text { pat }\end{array}$ & $\begin{array}{l}\text { (\%) of } \\
\text { ients }\end{array}$ & $\begin{array}{l}95 \% \mathrm{Cl} \text { for } \\
\text { percentage }\end{array}$ & $\begin{array}{l}\text { No. }(\%) \text { of } \\
\text { patients }\end{array}$ & $\begin{array}{l}95 \% \mathrm{Cl} \text { for } \\
\text { percentage }\end{array}$ \\
\hline Surgical & 680 & 2161 & 539 (79.3) & $72.7-85.9$ & 54 & (7.9) & $5.8-10.0$ & $133 \quad(19.6)$ & $8.9-30.2$ \\
\hline Medical & 1212 & 4162 & $600(49.5)$ & $41.4-57.7$ & 119 & $(9.8)$ & $4.2-15.4$ & $295 \quad(24.3)$ & $8.0-40.7$ \\
\hline $\mathrm{NICU}$ & 296 & 2135 & 133 (44.9) & $33.4-56.5$ & 32 & $(10.8)$ & $1.4-20.2$ & $6 \quad(2.0)$ & $0.0-4.3$ \\
\hline PICU & 799 & 10471 & 708 (88.6) & $85.5-91.8$ & 441 & $(55.2)$ & $45.2-65.2$ & $150 \quad(18.8)$ & $5.1-32.4$ \\
\hline \multicolumn{10}{|c|}{$\begin{array}{l}\text { Note: } \mathrm{Cl}=\text { confidence interval, } \mathrm{NICU}=\text { neonatal intensive care unit, } \mathrm{PICU}=\text { pediatric intensive care unit. } \\
{ }^{*} \text { Design-based } \chi^{2} \text { analysis with } 95 \% \mathrm{Cls} \text {. Significant } p \text { values indicate differences across types of units with respect to each pain management intervention. } \\
\text { †Any pharmacologic intervention: } p<0.001 \text {. } \\
\text { †Any physical intervention: } p=0.07 \text {. } \\
\text { §Any psychologic intervention: } p=0.19 \text {. }\end{array}$} \\
\hline
\end{tabular}


consideration of the need for painful procedures for pediatric inpatients and the importance of ensuring a balanced array of pharmacologic and nonpharmacologic interventions should be emphasized during health care professionals' training. Current evidence-based guidelines for dealing with procedural pain and future research using prospective study designs should address and reflect the benefits of documentation that will allow for precise determination of the efficacy of various pain management approaches. Given that units in our study that accessed specialist pain services administered analgesia less frequently, ongoing education for health care professionals about the role of pain specialists, as well as the evidence-based effectiveness of both pharmacologic and nonpharmacologic interventions within different hospital units, is required. Changing the behaviour of health care professionals is complex and challenging. Therefore, solutions to reduce the pain that children experience while in hospital must involve a social dialogue that engages clinicians and researchers and customization of interactive strategies (i.e., strategies involving interaction between health care professionals) that are consistent with the practice culture on the unit and the very fabric of the caregiving model.

\section{References}

1. Carbajal R, Rousset A, Danan C, et al. Epidemiology and treatment of painful procedures in neonates in intensive care units. JAMA 2008;300:60-70.

2. Stinson J, Yamada J, Dickson A, et al. Review of systematic reviews on acute procedural pain in children in the hospital setting. Pain Res Manag 2008;13:51-7.

3. Yamada J, Stinson J, Lamba J, et al. A review of systematic reviews on pain interventions in hospitalized infants. Pain Res Manag 2008;13:413-20.

4. Grunau RE, Tu MT. Long-term consequences of pain in human neonates. In: Anand KJS, Stevens BJ, McGrath PJ, editors. Pain in neonates and infants. 3rd ed. Philadelphia (PA): Elsevier; 2007. p. $45-55$

5. Hermann C, Hohmeister J, Demirakca S, et al. Long-term alteration of pain sensitivity in school-aged children with early pain experiences. Pain 2006;125:278-85.

6. Batton DG, Barrington KJ, Wallman C. Prevention and management of pain in the neonate: an update. Pediatrics 2006;118 2231-41.

7. Berry PH, Dahl JL. Making pain assessment and management a healthcare system priority through the new JCAHO pain standards. J Pharm Care Pain Symptom Control 2000;8:5-20.

8. American Academy of Pediatrics, Committee on Fetus and Newborn, Committee on Drugs, Section on Anesthesiology, Section on Surgery; Canadian Pediatric Society, Fetus and Newborn Committee. Prevention and management of pain and stress in the newborn infant. Pediatrics 2000;105:454-61.

9. Taylor EM, Boyer K, Campbell FA. Pain in hospitalized children: a prospective cross-sectional survey of pain prevalence, intensity, assessment and management in a Canadian pediatric teaching hospital. Pain Res Manag 2008;13:25-32.

10. Johnston CC, Barrington KJ, Taddio A, et al. Comfort measures for pain in Canadian NICU's: Have we improved in the past decade? [abstract]. In: Proceedings of the 19th annual meeting of the Pediatric Academic Society; 2008 May 3-8; Honolulu (HI). E-PAS2008:634454.13. Available: www.abstracts2view .com/pasall/ (accessed 2011 Mar. 1).

11. Porter FL, Wolf CM, Gold J, et al. Pain and pain management in newborn infants: a survey of physicians and nurses. Pediatrics 1997;100:626-32.
12. Porter FL, Wolf CM, Miller JP. Procedural pain in newborn infants: the influence of intensity and development. Pediatrics 1999; 104:e13

13. Lohr SL. Variance estimation in complex surveys. In: Sampling: design and analysis. Pacific Grove (CA): Duxbury Press; 1999. p. 289-293.

14. Hubbard AE, Ahern J, Fleischer NL, et al. To GEE or not to GEE: comparing population average and mixed models for estimating the associations between neighbourhood risk factors and health. Epidemiology 2010;21:467-74.

15. Zempsky WT, Schechter NL. What's new in the management of pain in children? Pediatr Rev 2003;24:337-48.

16. von Baeyer CL, Marche TA, Rocha EM, et al. Children's memory for pain: overview and implication for practices. J Pain 2004;5: 241-9.

17. Simons SH, van Dijk M, Anand KS, et al. Do we still hurt newborn babies? A prospective study of procedural pain and analgesia in neonates. Arch Pediatr Adolesc Med 2003;157:1058-64.

18. Harrison D, Loughnan P, Manias E, et al. Analgesics administered during minor painful procedures in a cohort of hospitalized infants: a prospective clinical audit. J Pain 2009;10:715-22.

19. Stevens B, McGrath P, Ballantyne M, et al. Influence of risk of neurological impairment and procedure invasiveness on health professionals' assessment and management of procedural pain in neonates. Eur J Pain 2010;14:735-41.

20. Taylor EM, Boyer K, Campbell FA. Pain in hospitalized children: a prospective cross-sectional survey of pain prevalence, intensity, assessment and management in a tertiary referral Canadian teaching hospital. Pain Res Manage 2008;13:25-32.

21. Schechter NL, Allen DA, Hanson K. Status of pediatric pain control: a comparison of hospital analgesic usage in children and adults. Pediatrics 1986;77:11-5.

22. Gadish HS, Gonzales HL, Hayes JS. Factors affecting nurses decisions to administer pediatric pain medication postoperatively. J Pediatr Nurs 1988;3:383-90.

23. Jacob E, Puntillo KA. A survey of nursing practice in the assessment and management of pain in children. Pediatr Nurs 1999; 25:278-86.

24. Dowde SJ. Pharmacology of analgesic drugs. In: Twycross A, Dowden SJ, Bruce E, editors. Managing pain in children: a clinical guide. Oxford (UK): Wiley-Blackwell; 2009. p. 39-66.

25. Stevens B, Yamada J, Ohlsson A. Sucrose for analgesia in newborn infants undergoing painful procedures. Cochrane Database Syst Rev 2010;(1):CD001069.

26. McDonnell A, Nicholl J, Read SM. Acute pain teams and the management of postoperative pain: a systematic review and meta-analysis. $J A d v$ Nurs 2003;41:261-73.

27. Werner MU, Soholm L, Rotboll-Nielsen P, et al. Does an acute pain service improve postoperative outcome? Anesth Analg 2002;95:1361-72.

28. Dufault MA, Sullivan M. A collaborative research utilization approach to evaluate the effects of pain management standards on patient outcomes. J Prof Nurs 2000;16:240-50.

Affiliations: From The Hospital for Sick Children (Stevens, Abbott, Yamada, Stinson, Taddio, Barwick, Campbell), Toronto, Ont.; the University of Toronto (Stevens, Yamada, Harrison, Stinson, Taddio, Barwick, Campbell), Toronto, Ont.; the Royal Children's Hospital (Harrison), Melbourne, Australia; the IWK Health Centre (Latimer, Finley), Halifax, NS; Dalhousie University (Latimer, Finley), Halifax, NS; the University of Alberta (Scott), Edmonton, Alta.; and the Children's Hospital of Eastern Ontario (Rashotte), Ottawa, Ont.

Contributors: Bonnie J. Stevens, Laura K. Abbott, Janet Yamada, Jennifer Stinson and Fiona Campbell contributed to the design of the study. Bonnie J. Stevens, Laura K. Abbott, Shannon D. Scott, Judith Rashotte and G. Allen Finley participated in the acquisition of the data. Bonnie J. Stevens, Laura K. Abbott, Janet Yamada, Denise Harrison, Jennifer Stinson, Anna Taddio, Melanie Barwick, Margot Latimer, Fiona Campbell and G. Allen Finley contributed to the analysis and interpretation of the data. Bonnie J. Stevens, Laura K. Abbott, Janet Yamada, Denise Harrison, Melanie Barwick, Judith Rashotte and Fiona Campbell drafted the manuscript. All authors critically reviewed the manuscript for important intellectual content. Bonnie J. Stevens, Janet Yamada, Melanie Barwick and Margot Latimer were involved in obtaining funding for the study. Bonnie J. Stevens, Laura K. Abbott, Janet Yamada, Jennifer Stinson, Anna Taddio, 
Melanie Barwick, Margot Latimer, Shannon D. Scott and G. Allen Finley provided administrative, technical or material support. Bonnie J. Stevens, Laura K. Abbott, Shannon D. Scott, Judith Rashotte and Fiona Campbell provided supervision. All authors approved the final version of the manuscript submitted for publication. Bonnie J. Stevens had full access to all of the data in the study and takes responsibility for the integrity of the data and the accuracy of the data analysis.

CIHR Team in Children's Pain: The following additional members of the CIHR Team in Children's Pain made substantial contributions to the study design, acquisition of data, analysis and interpretation of data, revision of the manuscript and other aspects of the study (e.g., acquisition of funding, administrative, technical or material support, supervision): Christine Chambers PhD, IWK Health Centre and Dalhousie University, Halifax, NS; Janice Cohen PhD, Children's Hospital of Eastern Ontario, Ottawa, Ont.; Greta Cummings RN $\mathrm{PhD}$, University of Alberta, Edmonton, Alta.; Carole A. Estabrooks RN PhD, University of Alberta, Edmonton, Alta.; Céleste Johnston RN DEd, McGill University, Montréal, Que.; Shoo Lee MD PhD, Mount Sinai Hospital, The Hospital for Sick Children, and the University of Toronto, Toronto, Ont.; Sylvie Le May RN PhD, CHU Sainte-Justine and Université de Montréal, Montréal, Que.; Patrick McGrath PhD,
IWK Health Centre, and Dalhousie University, Halifax, NS; Christina Rosmus RN MSc, The Montreal Children's Hospital, Montréal, Que.; Doris Sawatzky-Dickson RN MN, Children's Hospital of Winnipeg Health Sciences Centre, Winnipeg, Man.; Robyn Stremler RN PhD, University of Toronto, Toronto, Ont.; Anne Synnes MD, BC Children's Hospital and University of British Columbia, Vancouver, BC; Edith Villeneuve MD, CHU Sainte-Justine, Montréal, Que.; Fay Warnock RN PhD, BC Children's Hospital and University of British Columbia, Vancouver, BC; Andrew Willan PhD, The Hospital for Sick Children, Toronto, Ont.

Funding: Funding for this study was provided by the Canadian Institutes of Health Research (CTP-79854 and MOP-86605).

Acknowledgements: The authors gratefully acknowledge the following additional co-investigators of the CIHR Team in Children's Pain: Tricia Kavanagh and Souraya Sidani. They also thank the following individuals and groups: the research nurses who assisted with data acquisition at the participating hospitals; the Centre for Computational Biology at The Hospital for Sick Children for creating, housing and supporting the database; Jasna Grujic-Ciric for assistance with data management; J. Charles Victor for assistance with data analysis; and Jessica Holt for assistance with manuscript preparation. 